M.A. Roberts ${ }^{1}$

\title{
Does Climate Change Put Ethics on a Collision Course with Itself?
}

The purpose of this paper is to outline an intuitive ethics of climate change, one that understands our maximizing values, according to which it makes things better to make things better for people, to be tempered by our existential values, according to which existence is just different: making things better for a person by way of bringing that person into existence doesn't, on its own, make things better. Such a reconciliation, I argue, avoids the collision course we can otherwise anticipate between population ethics on the one hand and climate ethics on the other.

The work of reconciliation is commenced by reference to what we can call the person-affecting, or person-based, intuition. It's hard to get that intuition right; we need a formulation of the intuition that avoids the many pitfalls that many earlier formulations have fallen into. The principle I propose is, however, hardly immune to objection. In this paper, I consider and reply to two such objections both of which rely on the claim that probabilities are, in at least some cases, critical to moral evaluation. My counterargument will be that those objections evaporate just as soon as we clearly recognize that the probability facts underlying the one objection are very different from the probability facts underlying the other.

\footnotetext{
${ }^{1}$ The College of New Jersey, robertsm@tcnj.edu.
} 


\section{Plan for this paper}

The purpose of this paper is to outline an intuitive ethics of climate change. Seems easy, right? We simply list our intuitions and note how they apply to issues relating to climate change-or the environment, or resource allocation, or sustainability.

But there's an obstacle. Our intuitions on any close inspection seem at odds with themselves. They include, on the one hand, the basic maximizing idea that (other things equal) it makes things morally better to make things better for people. (A quick note: As I use the term person here, it includes many non-human animals and at the same time excludes many humans.) And they include, on the other, what I will call the existential constraint, the idea that bringing a person into existence, however worth having that existence might be, doesn't (other things equal) make things morally better.

Accordingly, as I see things, working out an intuitive ethics of climate change is a matter of both recognizing well-established maximizing values, including the basic maximizing idea, but understanding that those maximizing values are tempered by but not, after all, inconsistent with, our existential values, including the existential constraint.

I consider the task of reconciling our maximizing against our existential values a matter of practical urgency. Otherwise, we find, I think, ethics on a collision course with itself. For population ethics-in the main, and as the area has developed over the last couple of decades-urges us to attend, first and foremost, to a seemingly unchecked collection of maximizing values, values that push us into bringing, for as long as the sun shall sustain life, ever more additional people into existence. In dramatic contrast, climate ethics, in the main, and as that more interdisciplinary area has developed in more recent years, urges us to attend to our existential values, and thus pushes us to avoid the additional pressures on the climate and on the Earth's stock of natural resources that will predictably come with a swiftly increasing human population and thus avoid additional misery on behalf all those people who do now or will eventually exist.

Now, you may initially resist the idea that we have, alongside our maximizing values, certain existential values. (Many theorists do.) So in this paper I start with a case, what I'll call the Base Case, that I think is convincing on that point (part 2).

I'll then turn to the work of reconciliation (part 3). The principle I consider central to reconciliation is rooted in the well-known person-affecting, or personbased, intuition (PBI). But if the intuition is well-known it's also much maligned. My own view is that its negative press owes much to poor formulation. One goal of this paper, then, is to articulate the intuition in the form of a principle that I think we can successfully defend. 
And defend it I shall. Two of the most important of objections against the intuition are actually closely related and I will consider both those objections here (part 4). The first objection is based on what I will call the Better Chance Case. That objection rests on the compelling claim-the better chance claim-that a better chance of existence can and often does make things morally better in ways that we really can't quibble with. My sense is that the first objection captures a main reason why so many traditional maximizing consequentialists, and so many economists, find even the question whether the additional existence can, on its own, make things morally better perplexing. Of course it can, they say! For them, it's just obvious that the additional existence (other things equal) makes things better-it's just obvious that the basic requirements of rationality entail that result. I will argue, however, that it's a mistake to think that we can't consistently say both that the better chance of existence often does, in a certain way, make things better and that the actual fact of existence has no such salutary effect.

I then turn to the second objection (also in part 4). My guess is that the deep skepticism that many contemporary, post-Parfitian, consequentialists and most population ethicists share about the person-based intuition derives from this second objection, the nonidentity problem. I have argued elsewhere that it's a mistake to think that the nonidentity problem challenges the person-based intuition in any serious way, a mistake that, as it happens, is rooted in a misuse of the better chance claim. In this present paper, I will put a single instance of the most challenging among the nonidentity cases side by side against the Better Chance Case, and argue that out of that comparison a distinction clearly emerges, one that supports the plausible position that, although the better chance of existence often, in a certain way, makes things better, the choice under scrutiny in the nonidentity case makes things better in no way at all.

Conclusions are then noted (part 5).

\section{Why we need to reconcile maximizing against existential values.}

\subsection{The collision course between climate ethics and population ethics}

How do we count the cost of climate change? ${ }^{2}$ It seems clear that it counts against a given climate policy that that policy will foreseeably cause future generations to suffer as a result of the disease, dislocation and depletion of natural resources that

\footnotetext{
${ }^{2}$ I borrow this phrase from Broome 1992.
} 
we anticipate will come with significant increases in global temperatures. It seems clear that there is much to be said for a substantive, effective policy that would at least substantially reduce that suffering on behalf of future people.

That not insignificant proposition represents one aspect, one component, of our maximizing values, and on that proposition, I think, we can all surely agree-climate ethicist, population ethicist, traditional consequentialist, post-Parfitian consequentialist alike.

But now assume-hypothetically; this is actually a matter for empirical science to determine-that a swiftly increasing human population is identified as a significant contributor to increases in global temperatures and that the substantive, effective policy under consideration is one that would significantly limit population growth across the long-term future. Let's call that the "proactive population control policy." Under such a policy, many people who may well have existed under an alternate "no action policy" will be left out of existence altogether. Those people-in a future in which the "proactive population control policy" is implemented-won't literally suffer as a result of their nonexistence. Still, we should concede that their nonexistence is a kind of loss. Whatever we call it (loss, harm), it's a reduction to zero for each such person of whatever it is that makes life so precious to the one who lives. It's a reduction to zero in-we can say-the wellbeing level that person might otherwise accrue under the "no action policy."3

Among population ethicists, it seems that the dominant view is that those losses, the losses of the people who would remain merely possible under the "proactive population control policy," count against that policy. At least a little (90\%? 50\%?). The dominant view - the view of at least many (or most) population ethicists-is that the very maximizing values that tell us that the loss sustained by a future child when that child avoidably suffers under a "no action policy" counts against that policy also dictates that the loss sustained by a possible future child when that child never exists at all under a "proactive population control policy" must be counted against that policy.

The dominant view thus insists that the losses sustained by the future people who will exist and suffer under the one policy must be weighed against the losses sustained by the future people who will never exist at all under the alternate policy. The morally correct policy, then, as between the two would be the policy that sets us on the path toward the least bad future, that is, the best, future. The total utilitarian

\footnotetext{
${ }^{3}$ For purposes here, I leave the term wellbeing undefined other than to say that it is a measure of how good a given existence is for a given person. It's what makes life so precious to the one who lives. I also leave person undefined other than to note that I understand the term to include many non-human animals and to exclude many individuals that might be considered biologically human, e.g., a human body whose heart may be beating but whose cerebral cortex has ceased to function or a human embryo or an early human fetus that has yet to experience consciousness.
} 
principle, with or without some slight tweaking, might be put to work to determine just which future that is.

In contrast, climate ethics-and here is where I think we see our existential values at work-is going to have a quite different view. Climate ethics is going to declare, I think, that the kind of loss that comes with never existing at all under the “proactive population control policy” just doesn't count against that policy at all. If, hypothetically, the "proactive population control policy" is what maximally guards against the suffering of existing and future people, is, that is, what maximizes their wellbeing on balance, then it doesn't matter how many people will never exist under that policy. It's that policy that we should go with without further ado.

Thus the collision between population ethics on the one hand and climate ethics on the other. To avoid the conflict is-I am suggesting-to understand just how our maximizing values are tempered by our existential values; it's to reconcile the one set of values against the other.

We can't just say that, of course. We have to do it. I'll avoid hiding the ball on how that's to happen by noting that there's no reason in the world we can't distinguish not people as having moral status or not-that would be a mistake-but rather their losses as having moral significance or not. Under that distinction, the loss sustained when one never exists at all is morally very different from the loss sustained when one exists (whether now or later) and has less wellbeing than one accessibly could have had. (More on accessibility below.) In both cases, there's a loss. (I thus concede in this connection that one way of making things better for people is to bring them into worth-having existences (Existence Comparability) and that nonexistence, for those people, is a loss.) But it doesn't follow that those losses have the same moral significance. We can agree-our maximizing values operating in full force-that the one sort of loss clearly does have full moral significance and still say-now bringing our existential values to bear-that the other sort of loss has no moral significance at all.

And indeed the version of the person-based intuition I'll introduce later exactly supports such a Loss Distinction Thesis.

I'll just note that it's the work of Larry Temkin that has put the task of reconciliation on the table to begin with. ${ }^{4}$ It's his work that is convincing on the proposition that we aren't e.g. just maximizers, that we are existentialists as well, that we share a plurality of values that at various points seem to work against each other. This paper, then, can be viewed as a sort of homework assignment from Temkin: to explore how, in one little piece of the moral map, such a reconciliation might be achieved.

\footnotetext{
${ }^{4}$ Temkin 2012.
} 


\subsection{The Base Case}

You may initially resist the idea that we really do have, alongside our maximizing values, certain existential values. (Many theorists do.)

The Base Case (Graph 1) is, I think, convincing on that point. ${ }^{5}$ Here, a person $\mathrm{p}$ has a pretty rotten life in a given possible future fl under a given choice cl. Even so, life in fl bestows some benefits on p; p accrues some gains; p's life in fl isn't, on balance, less than worth living. Let's stipulate that the existing $\mathrm{p}$ has a wellbeing level in $\mathrm{fl}$ under cl that happens to fall at exactly the zero level. And now let's add that p's zero wellbeing level in $\mathrm{fl}$ is one that agents could have avoided on behalf of $\mathrm{p}$ by simply choosing $\mathrm{c} 2$ in place of $\mathrm{cl}$ and thus bringing about $\mathrm{f} 2$ in place of $\mathrm{fl}$. It's that fact about fl that worries us morally, the fact that p's loss in $\mathrm{fl}$ is entirely avoidable.

Now consider a distinct person, $\mathrm{q}$, who never exists at all in $\mathrm{fl}$ or in $\mathrm{f} 2$ but has a life clearly worth living in $\mathrm{f} 3$. We concede that the nonexistent $\mathrm{q}$ has a zero wellbeing level in $\mathrm{fl}$ and in $\mathrm{f} 2$. And we note that agents could have avoided that low wellbeing level on behalf of q by simply choosing $\mathrm{c} 3$ in place of $\mathrm{c} 1$ or $\mathrm{c} 2$ and thus bringing about $\mathrm{f} 3$ in place of $\mathrm{fl}$ or $\mathrm{f} 2$.

Do we think that f2 is better than fl? Surely we do (and here our "other things equal" condition is clearly met; no one beyond $\mathrm{p}$ and $\mathrm{q}$ is affected in any potentially morally relevant respect at all).

But now compare $\mathrm{f} 2$ against $\mathrm{f} 3$. One might think that, as between $\mathrm{f} 2$ and $\mathrm{f} 3$, the only issue is just who shall avoid the loss-just whose wellbeing is maximized. A principle of anonymity, or perhaps fairness; a principle that reflects our refusal to put

\footnotetext{
${ }^{5}$ Here and throughout this paper, fl, f2 etc. represent the outcomes, or possible worlds or futures, agents have the ability and the resources to bring about-that is, futures that exist as alternate available, or accessible, futures in the particular case. The concept of accessibility may vary depending on our interest in undertaking the evaluation. When our interest is to describe a relation of moral betterness between alternate futures-a ranking of those futures in terms of their overall moral betternessaccessibility represents more than a mere logical, or metaphysical, possibility, relative to fl, that $\mathrm{p}$ accrues more wellbeing or, relative to f3, that q exists. It's, rather, a relation that reflects the resources and the ability of moral agents, working as individuals or working together, to bring about (though not necessarily to make significantly probable) one future in place of another. Beyond an additional brief discussion of accessibility in part 2.5, the term is left undefined for purposes here. The futures represented in the graph are mutually exclusive and exhaust the accessible futures in the particular case. A name-p, q, etc.-written in italics and asterisked represents a person who never exists at all, and bold a person who does or will exist, in the indicated future. The utilities in the far left column indicate when one future is better for a person than another future-when, that is, a person has more wellbeing, on an overall lifetime basis, in one future than another. It's assumed for purposes here that the wellbeing level of a person who never exists in a given future is zero at that future-and thus that the future in which a person has an existence worth having is better for that person than a future in which that person never exists.

Thus I assume, for purposes here, Existence Comparability. On that assumption, it makes sense and can be true to say that a future in which a person exists is better (or possibly worse) for that person than any future in which that person never exists at all; by implication, a future in which a person never exists can be worse (or better) for that person than a future in which that person does or will exist.
} 
anyone's interests ahead of anyone else's (other things equal)-may seem to compel us to say that $\mathrm{f} 2$ and $\mathrm{f} 3$ are equally good. And we can't plausibly avoid application of that principle on the position that $\mathrm{p}$ somehow has a moral status that $\mathrm{q}$ lacks. Yes, $\mathrm{p}$ exists across the board ("necessarily") and q doesn't. But an array of cases convinces us that that fact doesn't bear on q's moral status and doesn't mean that it doesn't matter what happens to q. Ditto, even if we add to the case that $\mathrm{cl}$ is the choice actually made and $\mathrm{fl}$ is the future that actually unfolds.

\section{Graph 1: Base Case}

Here and throughout, c1, c2 etc. are choices, and f1, f2 etc. accessible outcomes, or worlds or futures, that may obtain under a given choice with a specified degree of probability (based on information available to agents just prior to choice); bold indicates the specified person does or will exist, italics with asterisk that the person never exists, in the specified future. Each graph exhausts the choices available to the agents and the futures accessible under those choices for the case. Gray, where it appears, indicates the choice in fact made and the future that in fact unfolds.

\begin{tabular}{|l|c|c|c|}
\hline & $\mathrm{c} 1$ & $\mathrm{c} 2$ & $\mathrm{c3}$ \\
\hline probability & 1 & 1 & 1 \\
\hline wellbeing & $\mathrm{f} 1$ & $\mathrm{f} 2$ & $\mathrm{f3}$ \\
\hline+10 & & $\mathbf{p}$ & $\mathbf{q}$ \\
\hline+0 & $\mathbf{p}, \mathrm{q}^{*}$ & $\mathrm{q}^{*}$ & $\mathbf{p}$ \\
\hline
\end{tabular}

All those points taken together may seem to make the conclusion that $\mathrm{f} 2$ and $\mathrm{f} 3 \mathrm{are}$ equally good-and that, with that, the conclusion that agents may do as they please between $\mathrm{c} 2$ and $\mathrm{c} 3-$ all but inescapable.

But I don't think we think that. I think we think that the one future f2 is better than $\mathrm{fl}$ and better than $\mathrm{f} 3$-that the one choice $\mathrm{c} 2$ is permissible and that $\mathrm{cl}$ and $\mathrm{c} 3$ are both wrong.

And in that evaluation-if that's our evaluation-we see our existential values at work. If we were pure maximizers, we'd say that $\mathrm{f} 2$ and $\mathrm{f} 3$ are equally good. But we're not. We don't think that leaving the existing $\mathrm{p}$ to suffer in f3-that p's loss in $\mathrm{f} 3$-is exactly counterbalanced by q's loss in $\mathrm{f} 2$. While the dimensions of the two losses are identical, we don't think they have the same moral significance.

The Base Case should I think leave us convinced that, alongside our maximizing values, we also have certain existential values.

We now turn to the work of reconciling the one set of values against the other. ${ }^{6}$

\footnotetext{
${ }^{6}$ Following Broome-though his proposal was made to show that the values of fairness and equality can be accommodated within an additive approach, and mine to show that our existential values can be accommodated within an additive approach-we can distinguish between wellbeing and contributive value (which Broome calls personal good). Broome 2015. Accordingly, if we decide at the end of the day
} 


\section{The person-based intuition}

\subsection{Parfit's formulation}

To fail to reconcile our maximizing against our existential values is to put ethics on a collision course with itself. It's to leave some of the dominant, foundational principles we find in population ethics at war with a plausible, indeed compelling, ethics of climate change.

The core principle that I think helps with the task of reconciliation-that in fact makes reconciliation possible-is what is called the person-affecting, or personbased, intuition (PBI). As articulated by Parfit decades ago, PBI provides that "what is bad" must be "bad for someone"-that is, for someone who does or will exist.7 Which is just another way of embracing (a) the existential idea that the loss one sustains by virtue of one's never having existed at all isn't, in itself, "bad," and while (b) quietly incorporating the maximizing idea that no loss at all on the part of any existing or future person means no wrong done and (c) opening the door to the further maximizing idea that still other sorts of losses, those sustained in futures in which one does or will exist, really are bad. As pure maximizers, we would take the position that losses, however accrued, through nonexistence or otherwise, are bad, and equally so. As maximizers whose values are tempered by our existential values, we'll say that the losses (not the people, just the losses) count very differently from the moral point of view: one sort of loss counts fully, the other sort not at all.

PBI seems intuitive enough. But it comes with a lot of bad press-I think at least in part because it often isn't formulated with an eye to avoiding objections that now, thanks to Temkin, Parfit, McMahan and many others, seem both obvious and pressing. (See Appendix A.) What I want to do here is go immediately to a more plausible formulation, one that I think at least arguably survives some of those objections. I'll then turn to two objections that we can't simply design around-that remain in force however carefully PBI is itself formulated.

\subsection{Expansive Very Narrow PBI (EVNPBI)}

Adding some detail, including some detail to what it is to be "bad" and what it is to be "bad for" someone, I suggest the following principle.

\footnotetext{
that the overall values of different futures are to be calculated by reference to an additive principle, then we will say that the contributive values (CVs) of p's and q's existences in, respectively, f2 and f4 are exactly the same, which are both exactly the same as the CV of q's nonexistence in f3, while the CV of p's existence in $\mathrm{fl}$ is lower. It being hard to fathom that the $\mathrm{CV}$ of $\mathrm{p}$ in $\mathrm{f} 2$ and $\mathrm{q}$ in $\mathrm{f} 4$ is less than zero, we shall have to say that the $\mathrm{CV}$ of existence for $\mathrm{p}$ in $\mathrm{fl}$ is actually negative despite the fact that p's wellbeing level in $\mathrm{fl}$ is non-negative, that is, zero.

${ }^{7}$ Parfit 1987 p. 363. Nicely formulated by Parfit, it was also brought to light by Narveson 1973.
} 
Expansive Very Narrow Person Based Intuition (EVNPBI). Where a future y is accessible to a future $\mathrm{x}, \mathrm{x}$ is morally worse than $\mathrm{y}$, and a choice made at $\mathrm{x}$ is wrong, only if there is a person $\mathrm{p}$ and a future $\mathrm{z}$ accessible to $\mathrm{x}$ such that $\mathrm{p}$ does or will exist in $\mathrm{x}$ and $\mathrm{x}$ is worse for $\mathrm{p}$ than $\mathrm{z}$ (where $\mathrm{z}$ may, but need not, be identical to $\mathrm{y}$ ).

This principle-EVNPBI-is, in certain ways, very narrow: it's just a necessary condition, and just a condition on wrongness and worseness, not on permissibility or betterness. At the same time, to determine whether its condition is satisfied, the principle requires an expansive inquiry: a look at the full array of alternate futures accessible relative to the future $\mathrm{x}$, and not just at the alternate future $\mathrm{y}$ we are working to compare $\mathrm{x}$ against.

\subsection{Note on accessibility}

EVNPBI makes use of a concept of accessibility. The notion of possibility alone will not give us the principle that we want. Consider the Three Outcome Case:

Graph 2: Three Outcome Case (Broome's Case)

\begin{tabular}{|c|c|c|c|}
\hline wellbeing & $\mathrm{f1}$ & $\mathrm{f2}$ & $\mathrm{f3}$ \\
\hline+10 & & & Billy \\
\hline+8 & & Billy & \\
\hline+0 & Billy* & & \\
\hline
\end{tabular}

Specifically, an appeal in this context to the concept of mere possibility won't let us take the position that $\mathrm{fl}$ and $\mathrm{f} 3$ are equally good. For it's surely possible that Billy has more wellbeing than Billy in fact has in f3. But the result that fl and f3 are equally good is seems clearly at the heart of $\mathrm{PBI}-$ a result any reasonably complete version of PBI should be able to generate.

We thus put the concept of accessibility to work instead. ${ }^{8}$ Applied to the Three Outcome Case, then, EVNPBI immediately instructs that $\mathrm{fl}$ and $\mathrm{f} 3$ are equally good. I then would take the further position, also a person-based position but outside the scope of EVNPBI, that the accessible future $\mathrm{f} 3$ reveals the moral deficiency in $\mathrm{f} 2$ that

\footnotetext{
${ }^{8}$ Feldman 1986, pp. 24-25. And, before that, to provide a semantics for modal logic (we never, e.g., say that necessarily $\mathrm{P}$ is false means that $\mathrm{P}$ is false in literally all possible worlds) Garson 2013, pp. 63-67.
} 
makes $\mathrm{f} 2$ worse, not just than $\mathrm{f} 3$, but also fl. We now have a complete, person-based account of the case. ${ }^{9}$

EVNPBI in hand, accessibility in two, we now turn to the two objections.

\section{Two objections}

\subsection{The Better Chance Case}

According to EVNPBI, the worth-having additional existence does not, other things equal, make a given future better. It seems, however, undeniable that in certain cases the better chance of existence does make things better.

Consider, for example, the Better Chance Case. Here, Harry's wellbeing at +8 in $\mathrm{fl}$ under $\mathrm{cl}$ is far from maximized; $\mathrm{f} 3$ under $\mathrm{c} 2$ is far better for Harry than $\mathrm{fl}$ under $\mathrm{cl}$. Yet we surely can agree that $\mathrm{cl}$ is permissible-that the probabilities at play in this case, the fact that the fertility pill substantially improves Harry's chances at existence, convert what would otherwise be a wrong choice into a perfectly permissible choice.

\section{Graph 3: Better Chance Case}

\begin{tabular}{|c|c|c|c|c|}
\hline & \multicolumn{2}{|c|}{ c1: take fertility pill } & \multicolumn{2}{c|}{ c2: take aspirin } \\
\hline probability & 0.1 & 0.9 & 0.0001 & 0.9999 \\
\hline wellbeing & $\mathrm{f} 1$ & $\mathrm{f} 2$ & $\mathrm{f3}$ & $\mathrm{f} 4$ \\
\hline+10 & & & Harry & \\
\hline+8 & Harry & & & \\
\hline+0 & & Harry $^{*}$ & & Harry $^{*}$ \\
\hline
\end{tabular}

\footnotetext{
${ }^{9}$ For purposes here, I leave accessibility undefined other than to note the following points. Accessibility is a relation between possible futures, such that if one future is accessible relative to another future in a given case, then necessarily the one future is accessible relative to that future (facts, that is, regarding accessibility being built into the details of each future, or world, and the details of each world themselves holding as a matter of necessity). (We can call that principle the accessibility axiom.) If agents, relative to one future $\mathrm{x}$, working as individuals or collectively, have the resources and ability to bring about a better future $\mathrm{y}$, and we accordingly say that $\mathrm{y}$ is accessible to $\mathrm{x}$, and if, in another case, agents in $\mathrm{x}$ don't have the resources and ability to bring about the better future $\mathrm{y}$, and thus that $\mathrm{y}$ isn't, in that case, accessible to $x$, we have in effect equivocated on " $x$ ": the " $x$ " in which the agents have the requisite resources and ability isn't identical to the " $x$ " in which they don't.

Thus it should be clear that EVNPBI isn't in violation of the principle of the independence of irrelevant alternatives, or independence for short, according to which one future's being worse than a second future does not depend on the existence or availability of any third future. If y is accessible relative to $\mathrm{x}$ and $z$ is not, and if its determined that $\mathrm{x}$ isn't worse than $\mathrm{y}$, then, according to the accessibility axiom, there will be no case in which $\mathrm{z} i$ is accessible relative to $\mathrm{x}$ and hence no violation of independence.
} 
But if Harry's better chance under $\mathrm{cl}$ at $\mathrm{fl}$ makes the otherwise wrong choice of $\mathrm{cl}$ at fl permissible, and if we think that cl's permissibility in this case turns on chance (in combination with wellbeing) making the otherwise worse-for-Harry fl better-forHarry, then doesn't that better chance, itself necessarily embedded, alongside cl, in fl, make fl better for Harry than, say, f3? Or f4? If we say yes, we'll then lose the implication from EVNPBI that $\mathrm{f} 3$ and $\mathrm{f} 4$ are at least as good as $\mathrm{fl}$ is-and with that the implication that $\mathrm{c} 2$ at $\mathrm{f} 3$ and $\mathrm{c} 2$ at $\mathrm{f} 4$ are both permissible.

Reply to the better chance objection. I think this argument against EVNPBI works, if, but only if, we understand the probabilities critical to moral analysis to bear on our evaluation of when one accessible future is better for a person than another and-from there-to bear on the evaluation of choice. But I think the argument fails if we instead understand the probabilities to bear exclusively on the evaluation of choice. (See Appendix B; distinction between the affect-the-future view and the affect-just-the-choice view; to preserve EVNPBI, we adopt the latter.)

Under that latter understanding, we can say that, in many cases and in certain ways, the better chance of existence can make things better. Thus in the Better Chance Case the better chance converts the otherwise wrong cl into a perfectly permissible cl. But we can also insist that the actual fact of existence doesn't have any salutary effect at all. Thus it doesn't make fl better than f2 or better than $\mathrm{f} 4$. That understanding would clarify that the ranking that EVNPBI generates before probabilities are taken into account and according to which $\mathrm{f} 2$, $\mathrm{f} 3$ and $\mathrm{f} 4$ are equally good and at least as good as fl is exactly the same as the ranking that EVNPBI generates after probabilities are taken into account. Moreover, EVNPBI on that latter understanding can as before leave the door open to still other person-based principles, perhaps a person-based Pareto principle, that could step in to say that, notwithstanding Harry's better chance, $\mathrm{fl}$ is actually worse than $\mathrm{f} 3$ and thus worse than $\mathrm{f} 2$ and $\mathrm{f} 4$ as well.

The upshot for permissibility of that latter understanding? EVNPBI tells us nothing about the permissibility of $\mathrm{cl}$ at $\mathrm{fl}$. But it does at least generate some results for us that nicely reflect both at least some of our maximizing values and at least some of our existential values: that $\mathrm{c} 2$ at $\mathrm{f} 3$ and $\mathrm{c} 2$ at $\mathrm{f} 4$ are both perfectly permissible.

Still, it is a problem that EVNPBI doesn't instruct that $\mathrm{cl}$ at $\mathrm{fl}$ is permissible. It means that EVNPBI arguably isn't even a reasonably complete person-based principle. For a reasonably complete principle would surely support, i.e. imply, that cl at fl is permissible. To remain true to the person-based intuition, however, any worthwhile extension of EVNPBI that generates the result that $\mathrm{cl}$ at $\mathrm{fl}$ is permissible must also take care not to simply toss the person-based results we've just noted EVNPBI so nicely generates: that $\mathrm{c} 2$ at $\mathrm{f} 3$ and $\mathrm{c} 2$ at $\mathrm{f} 4$ are permissible as well.

To that end I relied in some of my earlier work on a person-based appeal to the 
concept of expected value (EV). I now think that approach is problematic. We need another concept, another vehicle for balancing the better chance against the better outcome..$^{10}$ One option is the concept of probable value.

First, a definition. Where a choice $\mathrm{c}$ made at a future $\mathrm{f}$ creates a probability $\mathrm{n}$ that $\mathrm{p}$ will have the wellbeing level (WB) that $\mathrm{f}$ in fact assigns to $\mathrm{p}$, we can say that $f^{\prime}$ 's probable value ( $P V)$ for $p$ under $c$ is $\mathrm{n}(\mathrm{WB})$.

And now the principle:

Expansive Very Narrow Person Based Intuition + Probable Value $(E V N P B I+P V)$ :

Where $\mathrm{y}$ is accessible to $\mathrm{x}, \mathrm{x}$ is worse than $\mathrm{y}$ only if there is a person $\mathrm{p}$ and $\mathrm{a}$ future $\mathrm{z}$ accessible to $\mathrm{x}$ ' such that

$\mathrm{p}$ does or will exist in $\mathrm{x}$ and

$\mathrm{x}$ is worse for $\mathrm{p}$ than $\mathrm{z}$ (where $\mathrm{z}$ may, but need not, be identical to $\mathrm{y}$ ); and

$\mathrm{c}$ at $\mathrm{x}$ is wrong only if there is a person $\mathrm{p}$ and an alternate choice $\mathrm{c}^{\prime}$ at a future $\mathrm{y}$ accessible to $\mathrm{x}$ such that

$\mathrm{p}$ does or will exist in $\mathrm{x}$ and

$\mathrm{x}$ is worse for $\mathrm{p}$ than $\mathrm{y}$ and

$\mathrm{PV}$ of $\mathrm{c}$ at $\mathrm{x}$ for $\mathrm{p}<\mathrm{PV}$ of $\mathrm{c}^{\prime}$ at $\mathrm{y}$ for $\mathrm{p}$.

Applied to the Better Chance Case, EVNPBI+PV tells us that $\mathrm{cl}$ and $\mathrm{c} 2$, wherever performed, are permissible. $\mathrm{cl}$ is permissible in virtue of the fact that, wherever performed, $\mathrm{PV}(\mathrm{cl})$ is at least as great as PV(c2). And c2 performed at $\mathrm{f} 4$ is permissible in virtue of the fact that Harry's wellbeing in $\mathrm{f} 3$ is maximized. Finally, c2 performed at $\mathrm{f} 4$ is permissible in virtue of the fact that Harry never exists at all in $\mathrm{f} 4$.

That account of the Better Chance Case itself seems highly plausible, nicely reflecting our existential values while recognizing a clear sense in which a better chance at

\footnotetext{
${ }^{10}$ It's true that, by simply adding to EVNPBI a clause that deems a choice permissible in any case in which no alternate choice comes with more expected value than the one choice does for any existing or future person, we can easily provide a plausible account of the Better Chance Case itself. Since EV(c1) is at least as great-indeed, it's greater-than EV(c2), the new principle would immediately instruct that cl is permissible. Since we would just add the new clause, not substitute it for the clause that lets the agents off the hook when they (at the end of the day) succeed in maximizing wellbeing for the person or when the person never ends up existing at all, the principle would also instruct that c2 (wherever performed) is permissible.

But I now think that that approach is problematic, incorrectly implying in certain cases that a given choice is permissible in virtue of a microscopic chance of a truly wonderful outcome. Where both the future that in fact obtains is very bad for person-perhaps the wellbeing level is even in the negative range-and the probability that the choice under scrutiny would produce just that outcome is very high, that choice may well in fact be wrong.

Outlier cases support this critique. This issue was pointed out to me by Dean Spears.
} 
existence can make things better: neither the better chance of existence, nor the actual fact of existence, will make the future better, but it can easily make the otherwise wrong choice perfectly permissible. ${ }^{11}$

\subsection{The non-identity problem}

One quite challenging version of the nonidentity problem arises very naturally in the context of climate change. ${ }^{12}$

The concern is that $\mathrm{PBI}-$ whether understood by reference to EVNPBI+PV or any other construction of PBI that credibly takes probability into account-generates the highly implausible result that we, in effect, need do little and perhaps nothing at all to control the flow of carbon into the atmosphere since, whatever we do, and provided that we take both the chance of a given person's making it into existence as well as the wellbeing that person has in those futures in which he or she does exist, our choice will be maximizing for each future person who will ever exist at all. Looked at in that way, the "no carbon limit policy," the policy we anticipate will cause future people to suffer, which suffering, we said, should be counted against that policy, actually turns out to be maximizing for each such future person. For well known reasons: what would their chances of existence have been, had the future not unfolded pretty much just as it did under that "no carbon action” policy? The usual (if not clearly correct) answer: but for the "no carbon limit policy,” they'd have had almost no chance of ever existing at all. ${ }^{13}$

\footnotetext{
${ }^{11}$ As it stands, EVNPBI+PV won't account for many other cases we are surely interested in. Specifically, it will remain silent in cases in which a choice is clearly permissible given the probabilities, but where $\mathrm{PV}$ is relatively low in virtue of the fact that the probability that any one of two or more high wellbeing futures will unfold is relatively low.

That EVNPBI+PV is limited-that it doesn't generate results in the sort of case-was pointed out to me by Christopher J.G. Meacham.

That we will want, however, to extend EVNPBI+PV does not mean that there is anything amiss with EVNPBI+PV as it stands.

${ }^{12}$ See Broome 1992.

${ }^{13}$ Thus virtually all population ethicists-indeed, virtually all contemporary consequentialists-owe their thinking in connection with that question to Parfit. On that view, the sweeping policy changes agents would have needed to put into effect, many years prior to Gloria's coming into existence, to have alleviate the suffering that climate change will otherwise impose on her would have had the effect, not of making things better for Gloria, but rather only of bringing another person-a person nonidentical to Gloria-into existence in place of Gloria. Yes, that person would have been better off-climate-changerelated suffering, on that distinct person's behalf, having been alleviated-than Gloria is. But for Gloria herself we can only anticipate a very low probability of any better result-and a very high probability of her never existing at all.

The thinking behind that conclusion is itself rooted in what Kavka called the "precariousness" of existence (Kavka 1981, p. 93.): any little change in the history that leads up to any particular person coming into existence is likely to affect the "timing and manner" of all the conceptions that will then take place. Parfit 1987, pp. 351-379.
} 
On that way of looking at things, EVNPBI+PV immediately generates results that seem to us to be clearly false: that the "no carbon limit policy" is perfectly permissible.

That way of looking at the case is summed up in Climate Change/Nonidentity Case Version I (Graph 4). Let's suppose that agents in fact choose cl, a "no carbon limit policy" on climate change, and that the future $\mathrm{fl}$ in fact unfolds. Let's suppose, further, that Gloria is a person who does not yet but eventually will exist and suffer in $\mathrm{fl}$ under $\mathrm{cl}$ as a result of the disease, dislocation and natural resource shortage that take place under that "no carbon limit policy."

\section{Graph 4: Climate Change/Nonidentity Case Version I}

\begin{tabular}{|c|c|c|c|c|}
\hline & \multicolumn{2}{|c|}{$\begin{array}{c}\text { c1: } \\
\text { choice to continue carbon } \\
\text { emissions at current levels } \\
\text { over next five years } \\
\text { ("no carbon limit policy") }\end{array}$} & $\begin{array}{r}\text { c2: } \\
\text { choice to reduce significantly } \\
\text { carbon emissions over next } \\
\text { ("proactive years } \\
\text { policy") }\end{array}$ \\
\hline probability & 0.1 & 0.9 & 0.0001 & 0.9999 \\
\hline wellbeing & $\mathrm{f1}$ & $\mathrm{f2}$ & $\mathrm{f3}$ & $\mathrm{f} 4$ \\
\hline+10 & & & Gloria & \\
\hline+2 & Gloria & & & Gloria* \\
\hline+0 & & Gloria* & & \\
\hline
\end{tabular}

It's the probabilities that the case takes for granted-the probabilities displayed in Graph 4-that explain why it is thought that $\mathrm{cl}$ is maximizing for Gloria, despite the suffering she endures in $\mathrm{fl}$ under $\mathrm{cl}$ and despite the fact that she is worse off in $\mathrm{fl}$ than she is in f3. In the Better Chance Case, Harry's better chance of coming into existence under $\mathrm{cl}$ makes up for his lower wellbeing level under $\mathrm{cl}$ at fl. Similarly here, or so the argument goes, Gloria's better chance of coming into existence under cl makes up for her lower wellbeing level under cl at fl.

Reply to nonidentity objection. The comparison between the Better Chance Case and the Climate Change Case can help us, I think, identify a flaw in the thinking behind the logic of the nonidentity problem. ${ }^{14}$ Put most simply, the "no carbon limit

As the discussion in the text below should make clear, in my view the line of argument that concludes that the choice under scrutiny, taking wellbeing and probability into account, is better for Gloria is in fact deeply flawed.

${ }^{14}$ I have described that flaw in the thinking behind the nonidentity problem more detail elsewhere, in connection with Parfit's depletion and risky policy cases, Kavka's slave child and pleasure pill cases and cases involving historical injustices. See Roberts 2007 and 2009. 
policy" on climate change just isn't a fertility pill. Even as we recognize what Kavka called the precariousness of existence, we should be able to see that the "no carbon limit policy" - the choice of cl-doesn't actually increase Gloria's chances of coming into existence. That she does, ex hypothesi, eventually exist doesn't increase the probability, calculated as of that time just prior to choice and based on information then available to agents, of her existence.

The confusion has, I think, arisen because theorists naturally focus on what does happen, an irrelevant if concrete fact whether we think probabilities should be brought to bear via standard expected value theory or via my concept of probable value, and thus fail to focus on the relevant if abstract fact: the many ways the future might have unfolded under what we all agree to be the worse option-that is, the "no carbon limit policy." The fact is that, for each of the huge umbrellas of "no carbon limit policy" and "proactive carbon limit policy, implementation can be achieved in a vast number of distinct particular ways. Some of those ways will result in (perhaps they will actually determine) Gloria's coming into existence; many, many will result in her never existing at all. But we have no ground for thinking that the probability that Gloria will exist under $\mathrm{cl}$ is greater than the probability that she will exist under c2.

If anything, the hazards the "no carbon limit action" policy on climate change will unleash on future people may well make it less likely, not more likely, that Gloria will exist than would the more secure environment that we can anticipate under the "proactive carbon limit policy."15

Consider, then, the following Graph 5, which provides a more accurate picture of the probabilities in fact at stake in connection with the climate change.

The critical point is that the choice of cl leaves Gloria's chances of ever existing at all just as microscopically small (indeed, .0001 wildly overestimates those chances) as c2 does. For both choices, how the choice is implemented may determine one particular future fl rather than another. But until the future in fact unfolds, agents

\footnotetext{
${ }^{15}$ Similar, the Holocaust surely made the children, grandchildren and great-grandchildren less likely to come into existence rather than more likely to come into existence. (I owe this suggestion, an extension of my point that those children were no less likely to come into existence had the Holocaust never occurred, to Peter Singer.) If a person's coming into existence is highly precariousness in any case, surely it is made more so when a powerful regime becomes intent on annihilating that person's forebears.

Clearer thinking about the probabilities at stake in the different versions of the nonidentity problem can also help us sort through the different versions of the repugnant conclusion. Parfit 1987, pp. 381-390. Thus, where a policy of overpopulation has strained resources, leaving vast numbers of people with lives only barely worth living, when an alternate population policy would have left fewer people with lives well worth living, the question should not be: what is the probability that all those vast numbers of people would have existed and been better off? but rather: for any one such person who has been left with a life only barely worth living, would an alternate policy, one that resulted in ample resources, have made any less likely that that person would ever have existed at all?
} 
can't have any clear idea just what form implementation will take. Gloria's chances of existence are thus very, very small under c1-just as they are under $c 2$.

Graph 5: Climate Change/Nonidentity Case Version II

\begin{tabular}{|c|c|c|c|c|c|c|c|c|}
\hline \multirow[b]{2}{*}{ probability } & \multicolumn{4}{|c|}{$\begin{array}{l}\text { c1: } \\
\text { choice to continue carbon emissions at } \\
\text { current levels over next five years ("no } \\
\text { carbon limit policy") }\end{array}$} & \multicolumn{4}{|c|}{$\begin{array}{c}\text { c2: } \\
\text { choice significantly to reduce carbon } \\
\text { emissions over next five years ("proactive } \\
\text { carbon limit policy") }\end{array}$} \\
\hline & 0.0001 & 0.0001 & 0.0001 & $\ldots$ & 0.0001 & 0.0001 & 0.0001 & $\ldots$ \\
\hline $\begin{array}{l}\text { how choice } \\
\text { implemented }\end{array}$ & $\mathrm{i}_{1}(\mathrm{c} 1)$ & $\mathrm{i}_{2}(\mathrm{c} 1)$ & $\mathrm{i}_{3}(\mathrm{c} 1)$ & ... & $\mathrm{i}_{1}(\mathrm{c} 2)$ & $\mathrm{i}_{2}(\mathrm{c} 2)$ & $\mathrm{i}_{3}(\mathrm{c} 2)$ & $\ldots$ \\
\hline wellbeing & f1 & $f 2^{\prime}$ & $f 2^{\prime \prime}$ & $\ldots$ & f3 & f4' & $f 4^{\prime \prime}$ & $\ldots$ \\
\hline+10 & & & & & Gloria & & & \\
\hline+8 & Gloria & & & & & & & \\
\hline+0 & & Gloria* & Gloria* & Gloria* & & Gloria* & Gloria* & Gloria* \\
\hline
\end{tabular}

That means that EVNPBI+PV easily avoids the result that the choice of the "no carbon limit policy" cl at fl is permissible and thus opens the door for the result that that choice is wrong. For all of the necessary conditions on that choice being wrong-that Gloria, first and foremost, exists at fl; that an alternate future f3 create more wellbeing (more actual value) for Gloria than fl does; and that that same alternate future creates more probable value for Gloria than fl does-are fully satisfied.

\section{Conclusion}

It seems that, if we want it, we can retain the person-based intuition, in, for example, the form of EVNPBI+PV. Recognizing that principle helps us see how our maximizing values are not inconsistent with but rather are tempered by our existential values. That reconciliation, in turn, provides the basis for an intuitive ethics of climate change-one that avoids putting ethics on a collision course with itself and one that won't obligate, or allow, us to increase the suffering of the people who do or will exist on the altar of bringing ever more people into existence but that may well require us to understand climate change as among the most pressing moral issues of our time, with critical steps to be taken, now or never, to alleviate the suffering that future people will otherwise be forced to endure. 


\section{Appendix A}

Very Narrow $P B I$. Where a future $\mathrm{y}$ is accessible to $\mathrm{x}, \mathrm{x}$ is morally worse than $\mathrm{y}$, and a choice made at $\mathrm{x}$ is wrong, only if there is a person $\mathrm{p}$ such that $\mathrm{p}$ does or will exist in $\mathrm{x}$ and $\mathrm{x}$ makes things worse for $\mathrm{p}$.

One feature that makes this principle narrow is that it asserts only a condition on when a future is worse, not on when a future is better. It can only tell us that a future in which the worse off person never exists isn't worse; it can't tell us that a future in which the better off person never exists isn't better.

To see why it's important to narrow PBI in that way, consider Graph Al below (Wrongful Life).

Graph A1: Wrongful Life

\begin{tabular}{|c|c|c|}
\hline wellbeing & $\mathrm{f} 1$ & $\mathrm{f} 2$ \\
\hline+0 & & Payal* $^{*}$ \\
\hline-10 & Payal & \\
\hline
\end{tabular}

Payal's life in $\mathrm{fl}$ is thoroughly miserable; her wellbeing level is in the negative range. It's plausible to say that it would have been better for Payal herself had Payal never have existed at all and, for that reason, that $\mathrm{fl}$ is worse than $\mathrm{f} 2-$ that is, that $\mathrm{f} 2$ is better than $\mathrm{fl}$ But if a person for whom things are better must exist in a given future for that future to be better, then we can't say that. Thus: the narrow construction of PBI will in the end make for a more credible principle.

A second feature further narrows the principle. The principle provides only a necessary, and not a sufficient, condition on when a future is worse. Even if we carefully limit the application of such a sufficient condition, we run into trouble in cases in which the wellbeing or existence of still other people is at stake.

To see that point, consider Graph A2 (Double Wrongful Life).

Graph A2: Double Wrongful Life

\begin{tabular}{|c|c|c|}
\hline wellbeing & f1 & f2 \\
\hline+0 & George $^{*}$ & Payal $^{*}$ \\
\hline-10 & Payal & George \\
\hline
\end{tabular}


In this case, it is highly plausible that $\mathrm{fl}$ is exactly as good as f2. That means that the fact that Payal exists and suffers in $\mathrm{fl}$, and that her suffering can be avoided at no cost to anyone else who does or will exist in f1, is not sufficient to show that $\mathrm{fl}$ is worse than f2. ${ }^{16}$ A plausible, more complete person-based view will include person-based principles that provide sufficient as well as additional necessary conditions on worseness. But the plausible sufficient condition won't be one that mechanically tracks the mere necessary condition we have in Very Narrow PBI. ${ }^{17}$

A well-formulated PBI will thus be narrow-indeed, very narrow. But Very Narrow PBI itself is not a principle we can evaluate. For it's elliptical in a certain respect. A future that is worse must make things worse for an existing or future person. But worse for that person than what?

It may seem perfectly obvious how the ellipsis is to be completed (and has indeed seemed so to many philosophers ${ }^{18}$ ). To determine whether the condition on $\mathrm{x}$ being worse than y is satisfied, it may seem that PBI requires us to look no further than whether $\mathrm{x}$ is worse for an person who does or will exist in $\mathrm{x}$ than $y$. On that construction, our survey of the futures accessible to $\mathrm{x}$ for purposes of determining whether the condition is satisfied is highly restricted. Thus:

Highly Restricted Very Narrow PBI (HRVNPBI). Where a future y is accessible to a future $\mathrm{x}, \mathrm{x}$ is morally worse than $\mathrm{y}$, and a choice made at $\mathrm{x}$ is wrong, only if there is a person $\mathrm{p}$ such that $\mathrm{p}$ does or will exist in $\mathrm{x}$ and $\mathrm{x}$ is worse for $\mathrm{p}$ than $\mathrm{y}$.

That highly restricted construction of $\mathrm{PBI}-H R V N P B I$ for short-however, dooms PBI to failure.

Consider Graph A3 (Three Outcome Case). ${ }^{19}$

Graph A3: Three Outcome Case

\begin{tabular}{|c|c|c|c|}
\hline wellbeing & $f 1$ & $f 2$ & $f 3$ \\
\hline+10 & & & Billy \\
\hline+8 & & Billy & \\
\hline+0 & Billy* & & \\
\hline
\end{tabular}

\footnotetext{
${ }^{16}$ Other cases as well make this point. See Hare 2007. See also Roberts 201la and $2011 \mathrm{~b}$.

${ }^{17}$ See, however, Parfit 2018.

${ }^{18}$ See e.g. Parfit 2017.

${ }^{19}$ This case is from Broome, as is the line of reasoning itself. Broome 2004, pp. 140-149. But I use that line of reasoning here to support a conclusion other than the one Broome suggests.
} 
For PBI to remain credible, it must be understood as consistent with a highly plausible Pareto principle, one that is limited to the case where the population in one future is identical to the population of another future (we'll call it Same-People Pareto). According to that principle, since the populations of $\mathrm{f} 2$ and $\mathrm{f} 3$ are identical, and since $\mathrm{f} 2$ is worse for one person, Billy, and better for no one, $\mathrm{f} 2$ is worse than $\mathrm{f} 3$. At the same time, it's clear that $\mathrm{f} 2$ isn't worse for Billy than fl. (Since Billy has a life that is worth living in $\mathrm{f} 2$ and no life at all in $\mathrm{fl}$, if anything, $\mathrm{f} 2$ is better for Billy than f1.) Ditto for f3 as compared against fl. HRVNPBI thus implies both that f2 isn't worse than $\mathrm{fl}$ and that $\mathrm{f} 3$ isn't worse than fl. The principle, in addition, implies both that $\mathrm{fl}$ isn't worse than $\mathrm{f} 2$ and that $\mathrm{fl}$ isn't worse than $\mathrm{f} 3$. On those grounds we then infer that $\mathrm{fl}$ and $\mathrm{f} 2$, and $\mathrm{fl}$ and $\mathrm{f} 3$, are exactly as good as each other and, finally, that $\mathrm{f} 2$ is exactly as good as f3. But now we have an inconsistency. f2 can't be both exactly as good as $\mathrm{f} 3$ and worse than $\mathrm{f3}$. Something shall have to go. ${ }^{20}$

But it doesn't follow that what has to go is PBI. We can consistently instead reject HRVNPBI in favor of the position that, when it comes to the existence of an additional person, and our aim is to compare one future against another, it's not enough to ask whether the person is worse off in the one future than in the other. Rather, we must ask whether the person is avoidably worse off in the one future. And that requires a more searching inquiry-an inquiry into whether there's any further alternate accessible future that is better for that person. If there is, then the condition itself is satisfied.

Thus:

Expansive Very Narrow PBI (EVNPBI). Where a future y is accessible to a future $\mathrm{x}, \mathrm{x}$ is morally worse than $\mathrm{y}$, and a choice made at $\mathrm{x}$ is wrong, only if there is a person $\mathrm{p}$ and $\mathrm{a}$ future $\mathrm{z}$ accessible $\mathrm{x}$ such that $\mathrm{p}$ does or will exist in $\mathrm{x}$ and $\mathrm{x}$ is worse for $\mathrm{p}$ than $z$ (where $\mathrm{z}$ may, but need not, be identical to y).

Since Expansive Very Narrow PBI-EVNPBI for short-requires an inquiry into not just how Billy fares in $\mathrm{f} 2$ as compared against $f 1$ but also how Billy fares in $\mathrm{f} 2$ as compared against $f 3$, and since $\mathrm{f} 2$ is worse for Billy than $\mathrm{f} 3$, the necessary condition on f2's being worse than $f 1$ is satisfied. We thus avoid the result that $\mathrm{f} 2$ is at least as good as fl and thus avoid the inconsistency. That, in turn, leaves us free to adopt still other person-based principles-here, it's enough to adopt a combination of samepeople Pareto and various conceptual principles-that tell us that $\mathrm{f} 2$ is indeed worse than fl. EVNPBI tells us, moreover, that $\mathrm{fl}$ is exactly as good as f3.

\footnotetext{
${ }^{20}$ Broome himself insists that it is the neutrality intuition, his own take on PBI, that we must reject. Broome 2004, pp. 140-149. I agree with him that we must reject the neutrality intuition, which instructs that $\mathrm{f} 2$ is worse than fl. But it doesn't follow that we must reject EVNPBI.
} 
We are thus left with an account of the case that is both plausible and consistent: fl is exactly as good as f3, while f2 is worse than both. Agents are permitted to bring Billy into existence and permitted not to bring Billy into existence, but it would be wrong to bring Billy into existence and make things worse for him rather than better. One feature that makes this principle narrow is that it asserts only a condition on when a future is worse, not on when a future is better. It can only tell us that a future in which the worse off person never exists isn't worse; it can't tell us that a future in which the better off person never exists isn't better. 


\section{Appendix B}

But what do those shifting values actually work on? Does the probability-as a prior matter; foundationally-affect the value of the future in which the choice is made? Does it make one future better than another, such that a choice that ends in the one future is itself deemed better? Let's call the view that says that it does the affect-thefuture view.

Or does it leave the valuation of the future alone and instead act just on the choice itself? Does the probability affect just the value of the choice? Let's call the view that says that that is what is going on the affect-just-the-choice view.

If we aren't clear on which view is correct, then we will be unable to rank one future against another in cases in which the probability that a given choice will give rise to a given future is less than 1.

Consider, again, the Better Chance Case (Graph 3).

\section{Graph 3: Better Chance Case}

\begin{tabular}{|c|c|c|c|c|}
\hline & \multicolumn{2}{|c|}{ c1: take fertility pill } & \multicolumn{2}{c|}{ c2: take aspirin } \\
\hline probability & 0.1 & 0.9 & 0.0001 & 0.9999 \\
\hline wellbeing & $\mathrm{f1}$ & $\mathrm{f} 2$ & $\mathrm{f3}$ & $\mathrm{f} 4$ \\
\hline+10 & & & Harry & \\
\hline+8 & Harry & & & \\
\hline+0 & & Harry* & & Harry $^{*}$ \\
\hline
\end{tabular}

The shaded area here and in what follows means that agents choose $\mathrm{cl}$ and that $\mathrm{cl}$ in fact ends in $\mathrm{fl}-\mathrm{in}$, that is, Harry's coming into existence at a wellbeing level of +8 . Let's assume that $\mathrm{cl}$ at $\mathrm{fl}$ is permissible. That seems undeniable. While Harry's wellbeing level in $\mathrm{fl}$ accessibly could have been higher-that is, it is higher f3; f3 is better for Harry than $\mathrm{fl}$-the fact that $\mathrm{cl}$ increases his chances of ever coming into existence at all seems clearly to counterbalance that fact and renders cl permissible.

In addition, we should take for granted that the fact that Harry's probability of existence under $\mathrm{cl}$ is 0.1 is a fact embedded in the future $\mathrm{fl}$ along with cl itself. Similarly, the fact that Harry's probability of existence under c2 is 0.0001 is a fact embedded in the future f3 along with c2 itself. Those are simply some of the many empirical details that are included in $\mathrm{fl}$ and $\mathrm{f} 3$, respectively.

And now our question: Do those facts about probabilities increase the value of the future fl itself as compared against the future f3? Is, that is, the affect-the-future view correct? 
On the affect-the-future view, while Harry has less wellbeing in fl than in f3, we still have ample room to say that, given Harry's higher probability of existence under $\mathrm{cl}$, $\mathrm{fl}$ is better than $\mathrm{f} 3$-that is, that $\mathrm{f} 3$ is worse than $\mathrm{fl}$. Taking both wellbeing and probability into account, in other words, we have ample room to say that fl is all things considered better than $\mathrm{f} 3$-that is, that $\mathrm{f} 3$ is all things considered worse than $\mathrm{fl}$. Indeed, the difference in probability under $\mathrm{cl}$ and $\mathrm{c} 2$ being so great, and the difference in the wellbeing levels themselves being relatively small, it seems that any affect-the-future principle that takes both into account will generate the result that $\mathrm{fl}$ is better than $\mathrm{f3}$-that is, that $\mathrm{f} 3$ is worse than $\mathrm{fl}$.

We then compare f2 and f4. Harry doesn't exist in either f2 or f4, and so we say that Harry has exactly as much wellbeing in $\mathrm{f} 2$ as Harry has in $\mathrm{f} 4$. As noted earlier, however, the choice cl-along with the higher probability of Harry's existence that comes with that choice-is embedded among the factual details of f2. Similarly, the choice c2-along with its lower probability of Harry's existence-is embedded in $\mathrm{f} 4$. Under the affect-the-future view, we accordingly say that f2 is better than $\mathrm{f} 4$-that is, that $\mathrm{f} 4$ is worse than $\mathrm{f} 2$.

It would seem that, on that view, it's better to make the choice that increases the chances of existence for more people (there being nothing special about Harry) even if (within limits; the life must be worth living) that choice also reduces (perhaps dramatically) the individual wellbeing levels for all of those who do or will exist. Those results provide support for the surely correct view that cl is permissible.

Moreover, since, on the affect-the-future view, the future that cl will produce is better, whether that future happens to be fl or f2, than any alternate future $\mathrm{c} 2 \mathrm{might}$ have produced, it seems we can go further and say that $\mathrm{cl}$ is not just permissible but also obligatory. But that's just to say that $\mathrm{c} 2$ is itself wrong.

But that result isn't at all consistent with the picture that EVNPBI itself provides. EVNPBI implies that fl isn't better than $\mathrm{f} 3$ and that $\mathrm{f} 2$ isn't better than $\mathrm{f} 4$. Those facts would seem to support the position that $\mathrm{c} 2$ is permissible.

Now, the fact that EVNPBI supports the result that $\mathrm{c} 2$ is wrong isn't, on its own, a problem for EVNPBI. We have agreed only that it's highly plausible that $\mathrm{cl}$ is permissible. But we haven't yet said anything about the plausibility of the claim that c2 is wrong.

Nonetheless, a question remains: will a plausible, more complete person-based view-one that takes probabilities into account; one that recognizes that the better chance can, in some sense, make things morally better-be able to avoid the result that $\mathrm{f} 3$ is worse than $\mathrm{fl}$ and that $\mathrm{f} 4$ is worse than $\mathrm{f} 2$ ? Will it be able to avoid the result $\mathrm{cl}$ is wrong?

I don't see how it can on an affect-the-future view. But things change if we approach the problem from the perspective of the affect-just-the-choice view. On that 
view, what the probabilities affect is the evaluation of the choice and the choice alone; they leave untouched how the futures themselves are to be ranked. ${ }^{21}$

\section{References}

Broome, John 1992. Counting the Cost of Global Warming. White Horse Press.

Broome, John 2004. Weighing Lives. Oxford University Press.

Broome, John 2015. "General and Personal Good: Harsanyi’s Contribution to the Theory of Value.” In Iwao Hirose and Jonas Olson (eds.), The Oxford Handbook of Value Theory: 249-266.

Feldman, Fred 1986. Doing the Best We Can. Reidel.

Garson, James W. 2013. Modal Logic for Philosophers (2 ${ }^{\text {nd }}$ ed.). Cambridge University Press.

Hare, Caspar 2007. "Voices from Another World: Must We Respect the Interests of People Who Do Not, and Will Never, Exist?” Ethics 117: 498-523.

Kavka, Gregory 1981. “The Paradox of Future Individuals.” Philosophy \& Public Affairs 11: 93-112.

Narveson, Jan 1973. “Moral Problems of Population.” In Michael D. Bayles (ed.), Ethics and Population. Cambridge, Mass.: Schenkman.

Parfit, Derek 1987. Reasons and Persons. Oxford: Oxford University Press (originally published 1984).

Parfit, Derek 2017. "Future People, the Non-Identity Problem, and PersonAffecting Principles”, Philosophy \& Public Affairs 45, 2, 118-157.

Roberts, Melinda A. 2007. “The Nonidentity Fallacy: Harm, Probability and Another Look at Parfit's Depletion Example.” Utilitas 19: 267-311.

Roberts, Melinda A. 2009. "The Nonidentity Problem and the Two Envelope Problem.” In Harming Future Persons, eds. Melinda A. Roberts and D. Wasserman. Springer. Pp. 201-228.

Roberts, Melinda A. 2011a. “The Asymmetry: A Solution,” Theoria 77: 333-367.

\footnotetext{
${ }^{21}$ An earlier version of this paper was presented at Workshop on Sustainability and Future People (Umeå University, February 13-14, 2020). I am very grateful to the participants of that workshop for their comments on that paper.
} 
The Institute for Futures Studies. Working Paper 2021:9

Roberts, Melinda A. 2011b. "An Asymmetry in the Ethics of Procreation," Philosophy Compass 6/11: 765-776.

Temkin, Larry 2012. Rethinking the Good: Moral Ideals and the Nature of Practical Reasoning. Oxford: Oxford University Press. 